\title{
A Novel Natural Remedy for Increasing Milk Secretion During Lactation Period
}

\section{Rafie Hamidpour ${ }^{*}$, Luay Rashan ${ }^{2}$}

${ }^{1}$ Department of Herbal Medicine, Pars Bioscience Research Center, Leawood, Kansas, USA

${ }^{2}$ School of Medicine, Department of Histologist, University of Dhofar, Oman

*Corresponding author: Ra ie Hamidpour, Department of Herbal Medicine, Pars Bioscience Research Center, Leawood, Kansas, USA, Tel: (913) 432-0107; E-mail: ra ie@parsbioscience.com

\section{Retraction Note:}

The article entitled "A Novel Natural Remedy for Increasing Milk Secretion During Lactation Period," has been accepted for publication in the Herbal Medicine: Open Access considering the statements provided in the article as personal opinion of the author which was found not having any conflict or biasness towards anything. As the article was a perspective one, information provided by the author was considered as an opinion to be expressed through publication. Publisher took decision to make the article online solely based on the reviewers suggestion which considered the article not but a personal opinion of the author. However, it is found that the author have some personal concerns and issues, therefore, being retracted from the journal. 